Elliptische Elemente des Cometen $1889 \ldots$ (Brooks Juli 6).

Aus Juli 8, Juli 2 I und August 5 resultiren die folgenden Elemente :

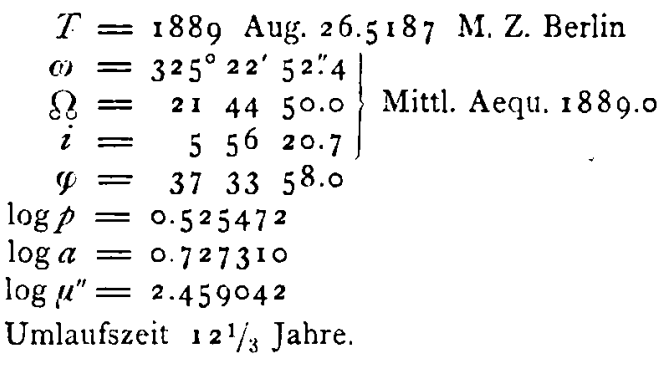

Umlaufszeit $121 / 3$ Jahre.

Währing 1889 Aug. 19.

Dr. $K . Z c l b r$.

\title{
Ueber die Benennung der beiden am 3. August 1889 entdeckten kleinen Planeten.
}

Nach einer Mittheilung des Herrn Perrotin ist die Entdeckungszeit des ron Herrn Charlois aufgefundenen Planeten auf Aug. 3 I $^{\mathrm{h}} 15^{\mathrm{m}}$ M. Z. Nizza festzusetzen, während Herr Dr. Palisa die in Nr. $29 \mathrm{r} 6$ angegebene erste Beobachtungszeit (Aug. $3 \mathbf{1}^{\mathrm{h}} \mathbf{3}^{\mathrm{m}}$ M. Z. Wien) als Entdeckungszeit anzusehen wünscht.

Vorausgesetzt, dass beide Planeten neu sind, wird also der Planet Charlois die Nummer (285), der Planet Palisa die Nummer (286) erhalten.

\section{Berichtigung zu „Aufforderung zu Meridianbeobachtungen des Mondkraters Mösting A“ in A. N. 2917.}

An Stelle der in Nr. 2917 p. 240 angegebenen Werthe fur die Reduction vom Krater auf die Mondmitte sind die folgenden Zahlen zu setzen:

\begin{tabular}{cccc}
\hline \multicolumn{1}{c}{ I889 } & $\alpha-\alpha_{0}$ & $\delta^{\prime}-\delta_{0}$ \\
\hline Sept. & 3 & -4.16 & $+41^{\prime \prime 2}$ \\
& 4 & -5.93 & +62.1 \\
& 5 & -8.11 & +77.7 \\
6 & -10.39 & +87.0 \\
7 & -.12 .41 & +90.2 \\
8 & -13.93 & +90.1 \\
9 & -14.88 & +89.0
\end{tabular}

\begin{tabular}{|c|c|c|}
\hline $\begin{array}{r}1889 \\
-\quad 1\end{array}$ & $a^{\prime}-\alpha_{0}$ & $\delta^{\prime}-\delta_{0}$ \\
\hline Sept. Io & $-15^{5.26}$ & +88.9 \\
\hline I I & -15.11 & +90.2 \\
\hline 12 & -14.44 & +92.3 \\
\hline 13 & -13.30 & +94.1 \\
\hline 14 & -11.74 & +93.7 \\
\hline I 5 & $\div 9.80$ & +89.7 \\
\hline 16 & -7.83 & +80.7 \\
\hline
\end{tabular}

Pag. 238 Z. I 4 u. I 3 v. u. statt : Krater - Mondcentrum - Erde lies : Krater - Mondcentrum - Beobachtungsort.

„, Z. 12-I I v. u. statt: der scheinbare Mondhalbmesser lies: der vom Beobachtungsort aus gesehene Mondhalbmesser.

Königsberg I 889 Aug. I 9.

7. Iranz.

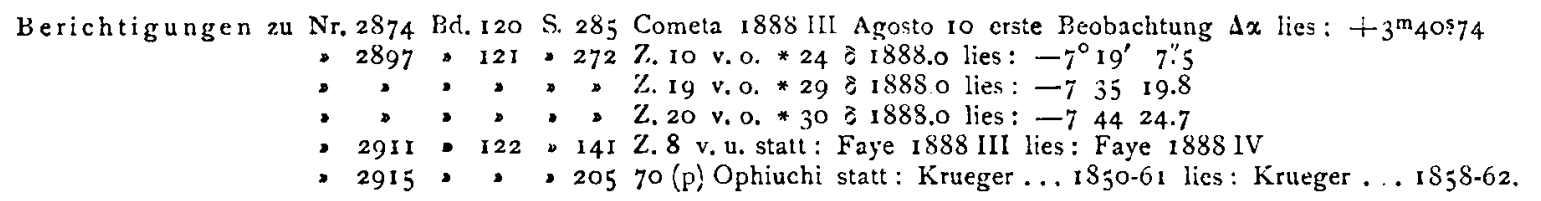

\section{In halt:}

Zu Nr. 2918. L. Swift. Catalogue No. 8 of Nebulae discovered at the Warner Observatory. 24I. - H. Kobold. Ueber das Verhalten des Repsold'schen Meridiankreises der Strassburger Sternwarte. 245. - F. Scheiner. Auszug aus einem Schreiben. 25 r. - E. E. Barnard. The Cluster G.C. 1420 and the Nebula N.G.C.2237. 253. - Beobachtungen des Cometen 1889... (Davidson) in Dresden und Genf. 253. - K. Zelbr. Elliptische Elemente des Cometen 1889... (Brooks Juli 6). 255. - Veber die Benennung der beiden am 3. August I 889 entdeckten kleinen Plancten. 255. - F. Franz. Berichtigung zu sufforderung zu Meridianbeobachtungen des Mondkraters Mösting A., 255. - Berichtigungen. 255.

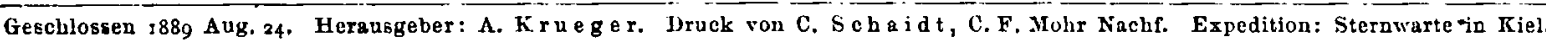

